\title{
Riboflavin Deficiency and Respiratory Flavoproteins of Bacillus subtilis
}

\author{
By M. B. KEMP AND P. B. GARLAND \\ Department of Biochemistry, Medical Sciences Institute, University of Dundee, \\ Dundee $D D_{\text {I }} 4 H N$
}

(Received 27 May 1974; revised 26 July 1974)

\begin{abstract}
SUMMAR Y
A mutant of Bacillus subtilis which required riboflavin for growth was grown with limiting or excess riboflavin. Riboflavin deficiency decreased the content of flavin, particularly of FMN in the particulate fraction. The activities of particulate succinate and NADH dehydrogenases also decreased, whereas $\alpha$-glycerophosphate dehydrogenase activity did not alter. When riboflavin was added back to a starved culture, the bacterial flavin content recovered quickly, even when chloramphenicol was present. Succinate dehydrogenase activity also recovered, but this increase was inhibited by chloramphenicol.
\end{abstract}

\section{INTRODUCTION}

Many of the protein components of the electron transport chain contain bound cofactors such as cytochromes, flavins, acid-labile sulphur or non-haem iron. In the absence of its cofactor thiamine, the apo-enzyme of pyruvate dehydrogenase in Escherichia coli is still synthesized (Dietrich \& Henning, 1970). However, for a component of a membrane there is the additional question as to whether an apo-protein can be incorporated into the membrane in the absence of its cofactor. A strain of Staphylococcus aureus unable to synthesize haem grew in the absence of haem and incorporated into the membrane apoprotein(s) which could be reconstituted in vitro by incubation with haem into functionally active nitrate reductase (Chang \& Lascelles, I963). The cytochrome(s) $b$ involved in the oxidation of NADH by $E$. coli could similarly be reconstituted (Haddock \& Shairer, 1973). By contrast, limitation of the growth of Candida utilis with iron led to a decrease in the activity of NADH dehydrogenase compared with that in a culture limited with glycerol. The activity could not be reconstituted in the absence of protein synthesis. Furthermore, there was much less of two of the polypeptide components of the membrane (Clegg \& Skyrme, 1973).

We investigated the consequences of limiting the supply of riboflavin on the synthesis and function of respiratory flavoproteins. The organism chosen was Bacillus subtilis. Unlike E. coli (Wilson \& Pardee, 1962), it is permeable to riboflavin, and auxotrophs requiring riboflavin were available (Bacher, Eggers \& Lingens, 1973). It also contains cytochromes and other components of a membrane-bound respiratory chain (Chaix \& Petit, I956; Miki, Sekuzu \& Okunuki, 1967; Tochikubo, I97I; Farrand \& Taber, I973).

\section{METHODS}

Bacterial strains and their culture. The wild-type strain of Bacillus subtilis used was $\mathrm{I} 68 \mathrm{M}$; it required tryptophan. The riboflavin auxotroph, H2OI, was derived from it. Both strains were obtained from Dr A. Bacher (Bacher et al., 1973). 
The strains were stored at room temperature on slants of A-K sporulation agar No. 2 (Baltimore Biological Laboratories, Baltimore, Maryland, U.S.A.). A loopful was streaked all over a plate of tryptose blood agar base (Oxoid) supplemented with glycerol or glucose $(5 \mathrm{~g} / \mathrm{l})$, and incubated overnight at $37^{\circ} \mathrm{C}$. This was used to inoculate Hutner's minimal medium (Ornston \& Stanier, I966) supplemented with tryptophan (20 $\mathrm{mg} / \mathrm{l})$ and various concentrations of riboflavin, and containing either glycerol $(5 \mathrm{~g} / \mathrm{l})$ with vitamin-free Casamino acids (Difco; I g/l) or glucose $(5 \mathrm{~g} / \mathrm{l})$. Portions $(500 \mathrm{ml})$ of inoculated medium, contained in 21 baffled conical flasks, were incubated at $37^{\circ} \mathrm{C}$ by shaking at $200 \mathrm{rev} . / \mathrm{min}$ on a gyratory shaker (LH Engineering Co. Ltd, Stoke Poges, Buckinghamshire). The cultures, at the concentrations given in Results, were harvested at room temperature, washed once in $10 \mathrm{mM}-\mathrm{KH}_{2} \mathrm{PO}_{4}-\mathrm{K}_{2} \mathrm{HPO}_{4}, \mathrm{pH} 6.8$, and the pellet was stored at $-\mathrm{I} 5^{\circ} \mathrm{C}$ overnight.

The density of a bacterial culture was measured as the extinction at $600 \mathrm{~nm}$, which was converted to $\mathrm{mg}$ dry weight $/ \mathrm{ml}$ using a calibration curve obtained for a culture harvested during exponential growth in glucose minimal medium and dried at $105{ }^{\circ} \mathrm{C}$.

Preparation of extracts. The frozen pellet, obtained as above, was thawed, resuspended in 4 vol. of $10 \mathrm{mM}-\mathrm{KH}_{2} \mathrm{PO}_{4}-\mathrm{K}_{2} \mathrm{HPO}_{4} \mathrm{pH} 6.8$ containing Io $\mathrm{mM}-\mathrm{MgCl}_{2}$, and shaken gently for $\mathrm{I} \mathrm{h}$ at $37^{\circ} \mathrm{C}$ with lysozyme $(200 \mathrm{mg} / \mathrm{l})$, RNase $(20 \mathrm{mg} / \mathrm{l})$ and DNase (Io $\left.\mathrm{mg} / \mathrm{l}\right)$; the method was a slight modification of that used by Farrand \& Taber (1973). The suspension was then centrifuged for $20 \mathrm{~min}$ at $35000 \mathrm{~g}$ and o to $10{ }^{\circ} \mathrm{C}$. The supernatant was designated the soluble fraction; the pellet was resuspended in the buffer solution used for breaking the bacteria and designated the particulate fraction.

Assay of flavins, cytochrome and protein. The amounts of FMN and FAD extracted with $10 \%(\mathrm{w} / \mathrm{v})$ trichloroacetic acid were measured by the method of Burch (1957), using riboflavin as the standard. The content of cytochrome $b+c$ was found from the difference spectrum, measured in a split-beam wavelength-scanning spectrophotometer (Yang \& Legallais, 1954), between a suspension treated with dithionite and one shaken in air. The difference in extinction between the peak at $558 \mathrm{~nm}$ and a reference wavelength $(575 \mathrm{~nm})$ was measured and a millimolar extinction coefficient of $201 / \mathrm{mmol} / \mathrm{cm}$ was assumed. Protein was measured by Lowry's method (Lowry, Rosebrough, Farr \& Randall, I951) using vacuum-dried bovine plasma albumen as a standard.

Assay of enzyme activities. All activities were assayed at $30{ }^{\circ} \mathrm{C}$ in $50 \mathrm{mM}-\mathrm{KH}_{2} \mathrm{PO}_{4^{-}}$ $\mathrm{K}_{2} \mathrm{HPO}_{4} \mathrm{pH} 6.8$ containing $10 \mathrm{mM}-\mathrm{MgCl}_{2}$. Rates of uptake of oxygen were measured with a Clark-type oxygen electrode (Yellow Springs Instruments, Yellow Springs, Ohio, U.S.A.). Dehydrogenases were assayed spectrophotometrically in a CE2O2 u.v. spectrophotometer (Cecil Instruments Ltd, Cambridge) coupled to a Vitatron UR40IL recorder (Fisons Scientific Apparatus, Loughborough). The electron acceptor was 2,6-dichlorophenolindophenol (DCIP, O.I mM), for which $\Delta E_{600}=201 / \mathrm{mmol} / \mathrm{cm}$. Cyanide (I mM) was present. Succinate dehydrogenase was assayed in the presence of varying concentrations of $N$ methylphenazonium methosulphate (PMS; $0.2,0.3$ and $0.6 \mathrm{mg} / \mathrm{ml}$ ) and the rate extrapolated to that at an infinite concentration of PMS. The concentrations of the substrates of the dehydrogenases and oxidases were: succinate, $20 \mathrm{mM}$; DL- $\alpha$-glycerophosphate, ro $\mathrm{mM}$; NADH for oxidase, $0.4 \mathrm{mg} / \mathrm{ml}$; NADH for dehydrogenase, $0.1 \mathrm{mg} / \mathrm{ml}$ (corrected for nonenzymic reaction).

Chemicals. Riboflavin, FMN, FAD, NADH, $\alpha$-glycerophosphate, DCIP, PMS, DNase and lysozyme were obtained from Sigma. 


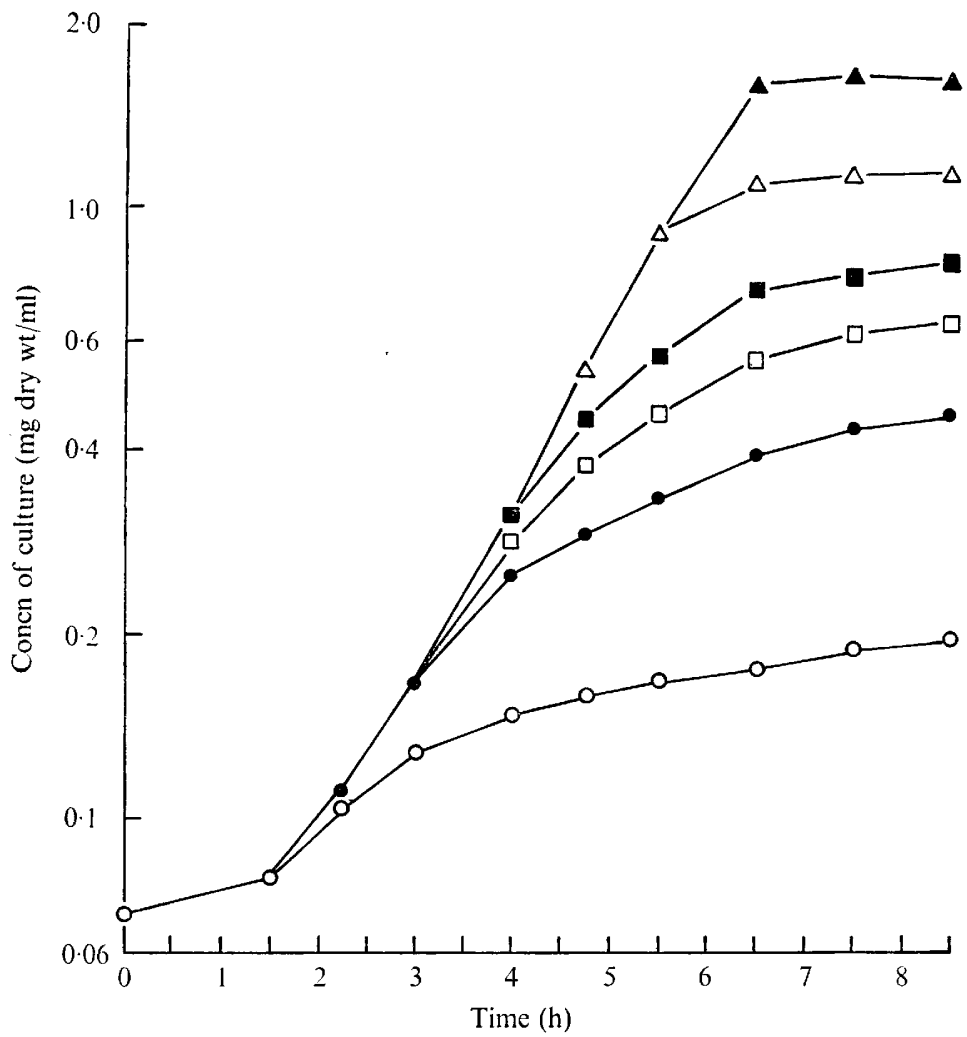

Fig. I. Growth curves of $B$. subtilis H2O in minimal glucose medium containing $(0) \circ,(0) 10$, $(\square) 20,(\square) 30,(\Delta) 50$ or $(\Delta) 500 \mu \mathrm{g}$ riboflavin/l. A culture previously growing with excess riboflavin $(500 \mu \mathrm{g} / \mathrm{l})$ was harvested at room temperature, resuspended in minimal medium and diluted into medium containing the above concentrations of riboflavin at time 0 .

\section{RESULTS}

Requirement of B. subtilis $\mathrm{H} 2 \mathrm{O}$ I for riboflavin

Mutant H2OI was grown on glucose minimal medium, supplemented with various levels of riboflavin (Fig. I). The growth rate was initially normal, but growth was eventually limited by riboflavin at concentrations below $50 \mu \mathrm{g} / \mathrm{l}$.

\section{Concentrations of flavins in bacteria starved of riboflavin}

Bacillus subtilis H2O I was starved of riboflavin in two ways. Firstly, the culture was grown with a limiting concentration of riboflavin $(30 \mu \mathrm{g} / 1)$ and compared with a culture grown with excess riboflavin $(500 \mu \mathrm{g} / \mathrm{l})$; the cultures were harvested as indicated in Fig. $2 a$. In the second method, a culture growing with excess riboflavin $(500 \mu \mathrm{g} / \mathrm{l})$ was diluted $\mathrm{I}: \mathrm{I} 7$ into medium containing either no or excess riboflavin and harvested as indicated in Fig. $2 b$. Both methods gave bacteria depleted in both FMN and FAD (Table I).

The respiratory system of cultures grown in glucose minimal medium

Under the growth conditions described in this paper, B. subtilis contained particulate cytochromes giving an $\alpha$-peak at $558 \mathrm{~nm}$, presumably composed of $b$ (including $o$ ) and $c$ 


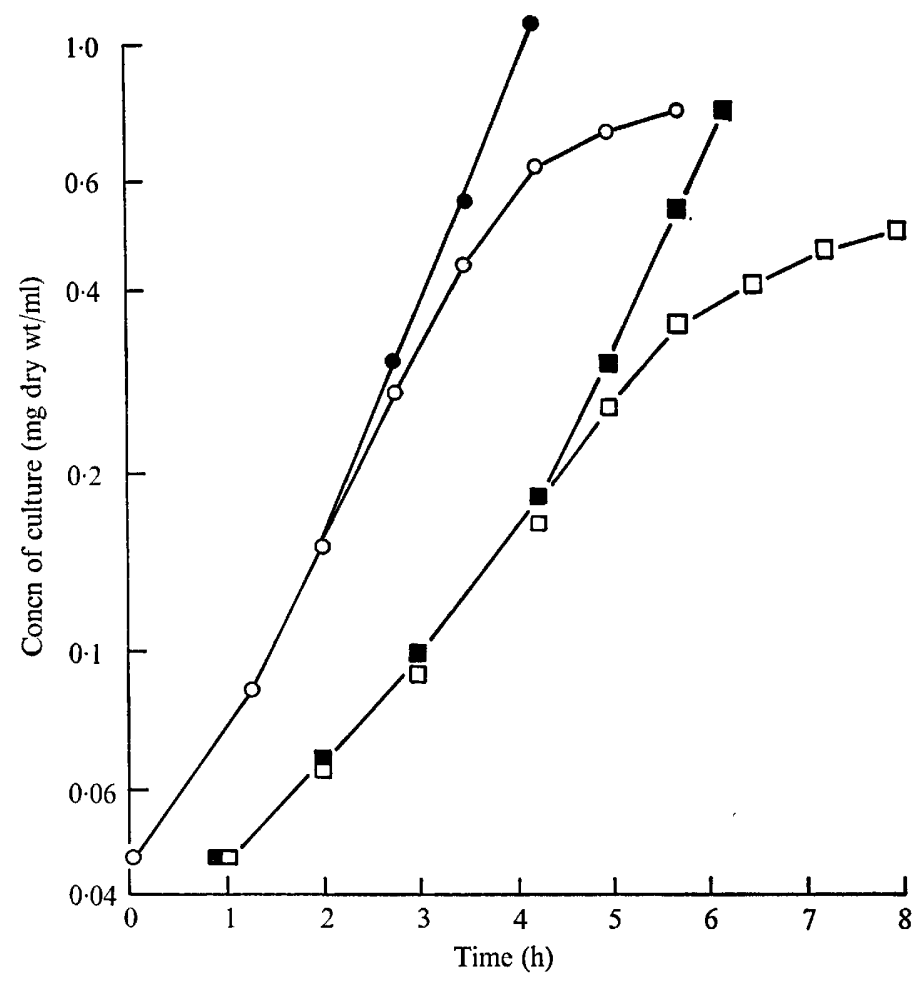

Fig. 2. Production of flavin-depleted B. subtilis H2OI. Cultures grown with $(O)$ limiting $(30 \mu \mathrm{g} / \mathrm{l})$ or $(\bullet)$ excess $(500 \mu \mathrm{g} / \mathrm{l})$ riboflavin. A culture growing with excess riboflavin was diluted 17 -fold into medium $(\square)$ without or $(\square)$ with riboflavin $(500 \mu \mathrm{g} / \mathrm{l})$. For biochemical assays, the cultures were harvested at the ends of the curves shown (see Table I).

Table I. Flavins, cytochrome and enzyme activities in cultures starved of riboflavin Bacteria were grown as in Fig. 2.

\begin{tabular}{|c|c|c|c|c|}
\hline \multirow[b]{2}{*}{ FAD $^{*}$} & \multicolumn{2}{|c|}{ Bacteria grown with riboflavin } & \multicolumn{2}{|c|}{ Bacteria diluted $\mathrm{I}: \mathrm{I} 7$ into medium: } \\
\hline & Limiting & Excess & -Riboflavin & + Riboflavin \\
\hline Total & 0.18 & 0.33 & 0.13 & 0.30 \\
\hline Soluble & 0.18 & 0.30 & 0.10 & 0.27 \\
\hline Particulate & 0.18 & $0.4 \mathrm{I}$ & 0.16 & 0.35 \\
\hline $\mathrm{FMN}^{*}$ & & & & \\
\hline Total & 0.07 & $0.3 \mathrm{I}$ & $0.1 \mathrm{I}$ & 0.29 \\
\hline Soluble & 0.08 & 0.36 & 0.14 & 0.40 \\
\hline Particulate & 0.06 & 0.19 & 0.08 & 0.18 \\
\hline Cytochrome $b+c^{*}$ & 0.07 & 0.08 & 0.08 & 0.08 \\
\hline Succinate dehydrogenase $\uparrow$ & 0.017 & 0.050 & 0.027 & 0.048 \\
\hline NADH oxidase $\dagger$ & 0.14 & 0.22 & 0.14 & 0.25 \\
\hline NADH-DCIP dehydrogenase $\dagger$ & O.I I & 0.27 & 0.16 & 0.34 \\
\hline
\end{tabular}

* Expressed as $\mathrm{nmol} / \mathrm{mg}$ protein in fraction.

$\uparrow$ Enzyme activities are those of the particulate fraction, expressed as $\mu \mathrm{mol} / \mathrm{min} / \mathrm{mg}$ bacterial protein. 
Table 2. Effect of adding riboflavin to bacteria depleted of flavin

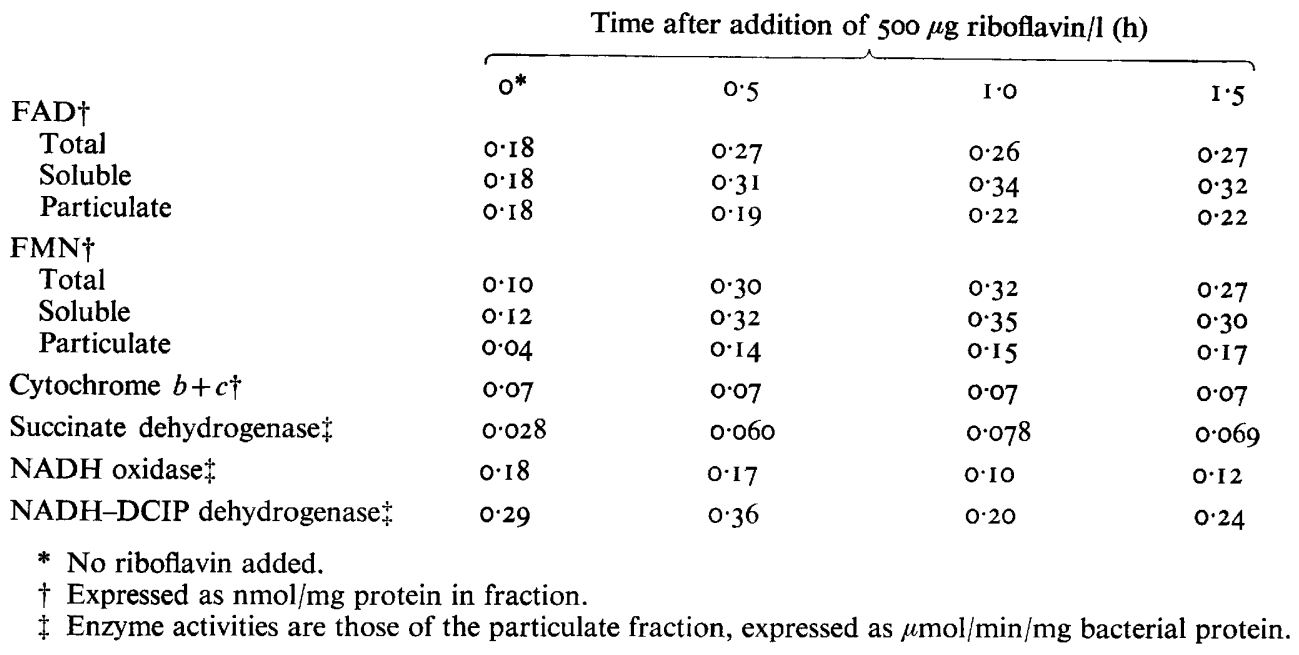

components (Chaix \& Petit, I956; Miki et al. 1967; Tochikubo, I97I). There was also a small, variable amount of an $a$ cytochrome ( $\alpha$-band at $605 \mathrm{~nm}$, Soret peak at $445 \mathrm{~nm}$ ). There was NADH oxidase in both particulate and soluble fractions; the soluble activity was similar to that described by Kogut \& Lightbown (1962) in that it was much stimulated by FMN (0.2 $\mathrm{nM}$ ) and not inhibited by cyanide (I $\mathrm{mM}$ ), whereas the particulate activity was not stimulated by FMN and was partially inhibited by I mM-cyanide. Both fractions contained NADH-DCIP dehydrogenase activity and there was succinate-DCIP dehydrogenase, stimulated by PMS, in the particulate fraction.

\section{Effects of riboflavin deficiency on the respiratory system}

The mutant H2OI was depleted of riboflavin by the methods given above (Fig. 2). The content of $b+c$ cytochrome did not decrease (Table I). The decreased flavin content was due to decreases in FMN and FAD contents of both the soluble and particulate fractions. The activities of succinate dehydrogenase, NADH-DCIP dehydrogenase and NADH oxidase all decreased when flavin was depleted.

\section{Recovery from depletion of flavin}

Since flavin depletion diminished both the flavin content and the enzyme activities of the particulate fraction, it seemed possible that riboflavin addition to the culture might restore both to normal.

The mutant was grown overnight (i.e. to stationary phase) with a limiting concentration of riboflavin. Riboflavin was then added and samples of the culture analysed at intervals (Table 2). The flavin content rose rapidly, due to an increase in FMN rather than FAD. Free riboflavin, which does not normally constitute a significant fraction of the bacterial flavin, would have been assayed as FMN. However, the apparent increase in FMN was shown not to be an accumulation of free riboflavin since only a negligible proportion was extracted into benzyl alcohol (Burch, 1957).

Riboflavin addition did not affect the cytochrome content (Table 2). Activities of NADH 
Table 3. Effect of chloramphenicol on recovery from flavin depletion

For experimental details, see text.

\begin{tabular}{|c|c|c|c|}
\hline & \multicolumn{3}{|c|}{ Additions to cultures at zero time: } \\
\hline & No addition: & Riboflavint: & $\begin{array}{l}\text { Riboflavin } \\
\text { chloramphenicol }\end{array}$ \\
\hline \multicolumn{4}{|l|}{ FAD* } \\
\hline Soluble & 0.15 & 0.26 & 0.17 \\
\hline Particulate & 0.16 & 0.19 & 0.17 \\
\hline \multicolumn{4}{|l|}{$\mathrm{FMN}^{*}$} \\
\hline Soluble & 0.08 & 0.34 & 0.33 \\
\hline Particulate & 0.04 & 0.23 & 0.25 \\
\hline Succinate dehydrogenase $\dagger$ & 0.019 & 0.045 & 0.015 \\
\hline NADH oxidase $\dagger$ & $0 \cdot 10$ & $0 \cdot 13$ & 0.13 \\
\hline NADH-DCIP dehydrogenase $\dagger$ & 0.08 & 0.15 & $0 \cdot 1 \mathrm{I}$ \\
\hline
\end{tabular}

* Expressed as nmol/mg protein in fraction.

$\uparrow$ Enzyme activities are those of the particulate fraction, expressed as $\mu \mathrm{mol} / \mathrm{min} / \mathrm{mg}$ bacterial protein.

+ Chloramphenicol added after $\mathrm{I} h$.

oxidase and NADH-DCIP dehydrogenase were not significantly changed but there was a twofold increase in the activity of succinate dehydrogenase.

The effects of riboflavin addition on the bacterial flavin content and on the activity of succinate dehydrogenase were not due simply to a presumed resumption of growth, since analogous experiments in which tryptophan was the limiting nutrient yielded no such changes.

\section{Effect of chloramphenicol on the recovery from riboflavin depletion}

It seemed plausible that, in the culture depleted of flavin, the apo-enzyme of succinate dehydrogenase might continue to be made. In that case recovery of the activity might not be depleted on the synthesis of new protein.

A riboflavin-depleted culture was divided into three portions two hours after its growth curve had diverged from that of a culture growing with excess riboflavin. The first portion received no riboflavin, but chloramphenicol $(\mathrm{I} 00 \mathrm{mg} / \mathrm{l})$ was added after $\mathrm{I} h$ when the culture was harvested (Table 3$)$. The second received riboflavin $(500 \mu \mathrm{g} / \mathrm{l})$ at zero time and chloramphenicol i $h$ later. The third received both riboflavin and chloramphenicol at zero time and was harvested $\mathrm{I} h$ later. Chloramphenicol had no effect on the dramatic increase in FMN seen when riboflavin was added back to the starved culture, but it completely blocked the increase in the activity of succinate dehydrogenase.

\section{Effect of riboflavin depletion on the activity of $\alpha$-glycerophosphate dehydrogenase}

When grown on glucose, $B$. subtilis does not need to use the tricarboxylic acid cycle, including succinate dehydrogenase, for carbon catabolism or the generation of ATP (Fortnagel \& Freese, I968; Ohne, Rutberg \& Hoch, 1973). Furthermore, the roles of the various soluble and particulate systems for oxidizing NADH are not clear. It seemed desirable to examine a flavoprotein enzyme which is involved in the catabolism of the compound used for growth. Mindich (1970) has shown that $\alpha$-glycerophosphate dehydrogenase is essential for glycerol catabolism. The properties of the enzyme are very similar to those of the analogous enzyme from Escherichia coli, which has been shown to contain FAD. The effects of riboflavin deficiency on the activity of this enzyme in extracts of mutant $\mathrm{H} 2 \mathrm{OI}$ grown on glycerol $(5 \mathrm{~g} / \mathrm{l})+$ Casamino acids ( $\mathrm{g} / \mathrm{l})$ were therefore examined. The riboflavin 


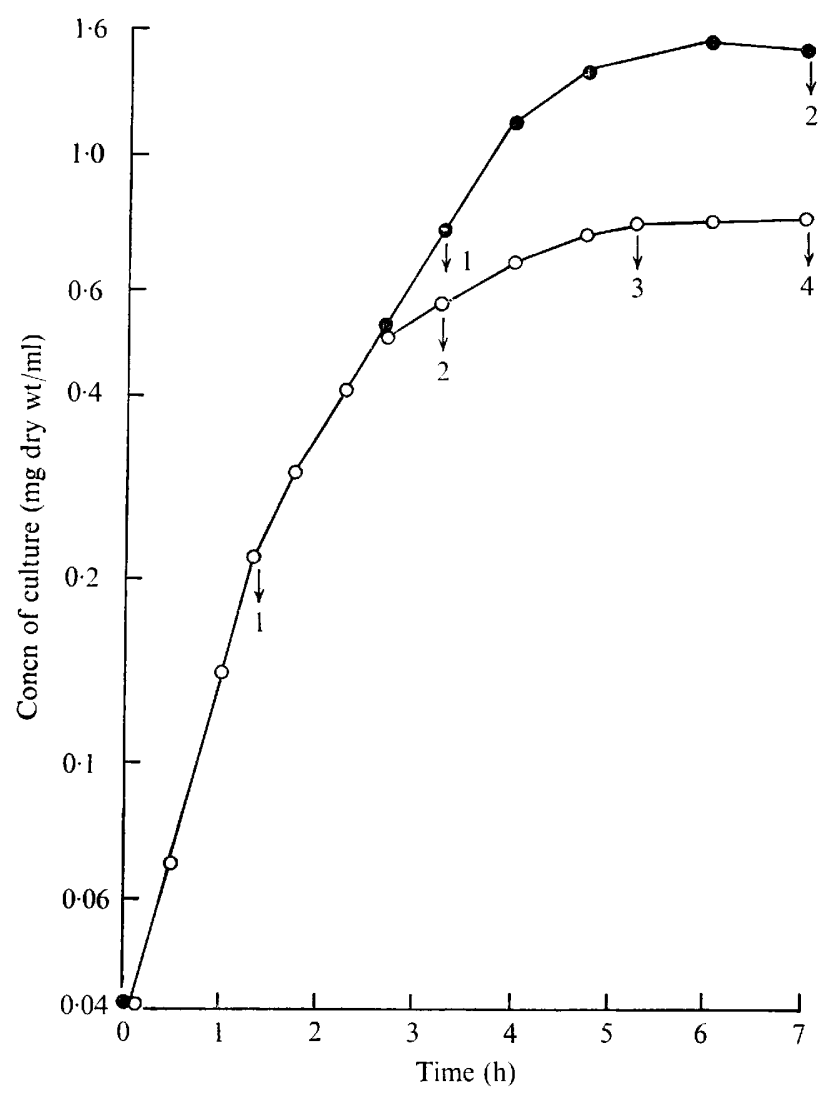

Fig. 3. Growth curves of $B$. subtilis $\mathrm{H} 2 \mathrm{OI}$ on glycerol ( $5 \mathrm{~g} / \mathrm{l})+$ Casamino acids (I $\mathrm{g} / \mathrm{l})$. ( $\bigcirc)$, Limiting riboflavin $(30 \mu \mathrm{g} / \mathrm{l}) ;(\Theta)$, excess riboflavin $(500 \mu \mathrm{g} / \mathrm{l})$. Samples were harvested at the points indicated by the arrows (for results see Table 4 ).

requirement was the same as that of cultures grown on glucose (Fig. 3). There was no significant difference in the activities of $\alpha$-glycerophosphate dehydrogenase or oxidase between cultures grown with limiting or excess riboflavin (Table 4), although there were the same differences in flavin content as in bacteria grown on glucose. Addition of excess riboflavin for I h during growth of a culture limited by riboflavin had little effect on the activity of $\alpha$-glycerophosphate dehydrogenase, whereas it increased the activity of succinate dehydrogenase just as it did with cultures growing on glucose.

\section{Attempted limitation of growth rate using derivatives of riboflavin}

Slow growth, limited by the supply of a desired nutrient, has often been achieved using a derivative of that nutrient which is only slowly converted into the nutrient or only enters the bacterium slowly. However, both FMN and FAD supported growth of mutant $\mathrm{H} 2 \mathrm{OI}$ as fast as and to the same extent as free riboflavin.

\section{Limitation of growth rate using a chemostat}

Steady growth, limited by a chosen nutrient, can best be achieved by using a chemostat. However, in the case of an auxotroph limited for its growth requirement, there is strong 


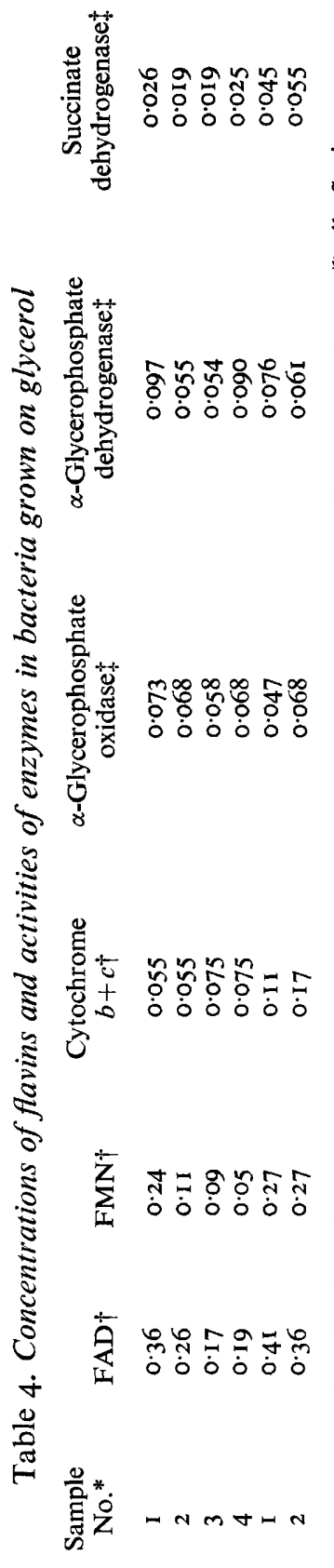

究

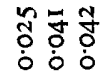

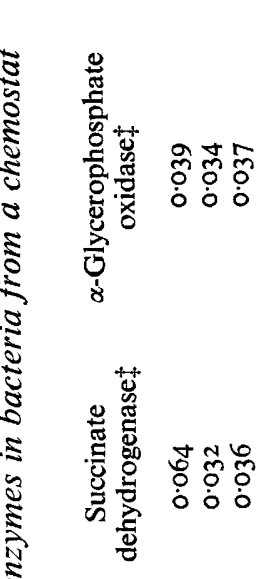

离

퐁

害

8

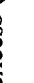

䟢

क्ष है

융

葛

$=$ 


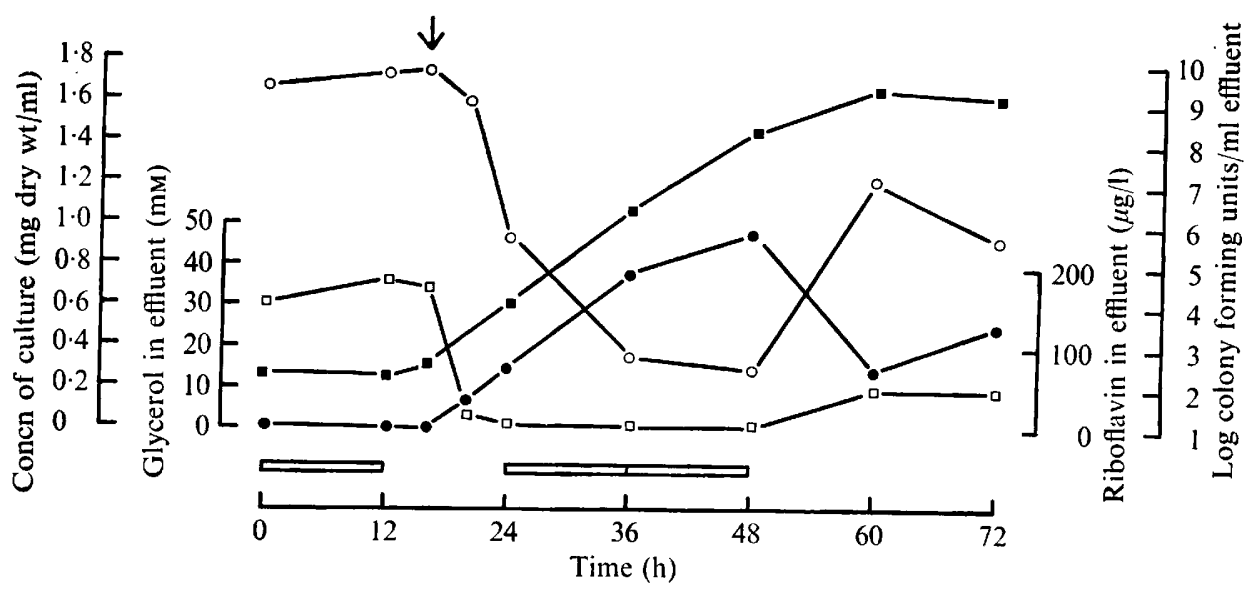

Fig. 4. Response of a culture of B. subtilis H2OI, growing in a chemostat, to a change in the limiting nutrient. The growth of the culture was limited initially by glycerol $(5 \mathrm{~g} / 1)$. At the time indicated by the arrow, the concentration of riboflavin in the medium was reduced from 500 to $30 \mu \mathrm{g} / \mathrm{l}$. $\bigcirc$, Density of culture (mg dry weight/ml); 9 , concentration (mM) of glycerol in the effluent; $\square$, concentration $(\mu \mathrm{g} / \mathrm{l})$ of riboflavin in the effluent; $\boldsymbol{\square}$, revertant colony-forming units $/ \mathrm{ml}$ of effluent. The bars indicate the periods of sampling for biochemical assays (Table 5).

pressure for the selection of a revertant. Mutants of $B$. subtilis which required riboflavin but did not revert were not available. Mutant H2OI was grown in the chemostat described by Light \& Garland (I97I). When the growth medium in the chemostat was changed from glycerol limitation ( $5 \mathrm{~g} / \mathrm{l}$; riboflavin $500 \mu \mathrm{g} / \mathrm{l}$ ) to riboflavin limitation (30 $\mu \mathrm{g} / \mathrm{l}$; glycerol $5 \mathrm{~g} / \mathrm{l})$ the density of the culture fell to a new low level (Fig. 4). The level of revertants increased exponentially with time, so that the steady-state persisted only for $32 \mathrm{~h}$ from the start of riboflavin limitation.

Limitation by riboflavin, at least at the dilution rate $\left(0 \cdot 2 \mathrm{~h}^{-1}\right)$ used in this study, did not decrease the bacterial flavin content once the organisms had become accustomed to the new limitation (Table 5). The ratio of FMN to FAD was higher than for the culture limited by glycerol, although, as in limitation in batch culture, the content of FMN in the particulate fraction was much decreased (not shown). Limitation by riboflavin, as in batch culture, decreased the activities of NADH oxidase and succinate dehydrogenase, but had no clear effect on $\alpha$-glycerophosphate dehydrogenase. Portions of the sample collected between the times 36 and $48 \mathrm{~h}$ (Fig. 4) were warmed to $37^{\circ} \mathrm{C}$ and incubated for $\mathrm{I} \mathrm{h}$ with riboflavin $(500 \mu \mathrm{g} / \mathrm{l})$ in the presence or absence of chloramphenicol ( $100 \mathrm{mg} / \mathrm{l})$. Riboflavin had no effect on flavin content or on the enzyme activities. This difference from the results with batch cultures may have been caused by the effluent from the chemostat being collected on ice and therefore spending up to $\mathrm{I} 2 \mathrm{~h}$ stationary at $0^{\circ} \mathrm{C}$, whereas the batch culture remained shaking at $37^{\circ} \mathrm{C}$ until the riboflavin was added.

\section{DISCUSSION}

Deficiency of certain nutrients in the growth medium can considerably reduce the content of some respiratory components (Light, 1972 $a, b$ ). Such a decrease in the concentration of a respiratory component could occur if the normal level is considerably higher kinetically than the requirement. This seems to apply to cytochrome oxidase in Candida utilis (Light, I972 b) and to menaquinone in B. subtilis (Farrand \& Taber, 1973). It does not appear to 
apply to ubiquinone (Gibson \& Cox, 1973) or to haem (Haddock, 1973) in E. coli. Alternatively, the concentration of a respiratory component may decrease if the role which it plays normally can be circumvented. Thus, strains of E. coli (Haddock \& Shairer, I973) and of Staphylococcus aureus (Chang \& Lascelles, 1963) which required an exogenous source of haem in order to make cytochromes, could grow fermentatively in the absence of the supplement.

In the present study, the effect of a deficiency of riboflavin on the activities of the flavoproteins studied was not dramatic. Possibly neither of the above conditions for observing a decrease applied. However, mutants of $B$. subtilis lacking succinate dehydrogenase can grow normally on glucose if aspartate ( $1.5 \mathrm{~mm}$ ) is added (Ohne et al. 1973). Growth of mutant H2OI on glucose + aspartate with limiting riboflavin gave the same decrease in activity of succinate dehydrogenase as was reported (Table I) in the absence of aspartate. In view of the many metabolic roles of flavoproteins, it is possible that some reaction other than those studied limited the growth of $B$. subtilis when starved of riboflavin. If this reaction had a much poorer affinity for flavin than the reactions studied in this paper, no effect of riboflavin deficiency on the latter would be expected.

In conclusion, a deficiency of riboflavin, unlike one of iron, sulphate, copper or haem, has not proved to be a useful way of manipulating the content and synthesis of components of the respiratory chain.

This work was generously supported by the Medical Research Council through grant no. G970/772/B.

\section{REFERENCES}

BACHeR, A., EgGers, U. \& Lingens, F. (1973). Genetic control of riboflavin synthetase in Bacillus subtilis. Archiv für Mikrobiologie 89, 73-77.

BURCH, H. B. (1957). Fluorimetric assay of FMN and FAD. Methods in Enzymology 3, 960-962.

Chaix, P. \& PeTIT, J. F. (1956). Étude de différents spectres cytochromiques de Bacillus subtilis. Biochimica et biophysica acta 22, 66-7I.

Chang, J. P. \& LASCelles, J. (1963). Nitrate reductase in cell-free extracts of a haem-requiring strain of Staphylococcus aureus. Biochemical Journal 89, 503-510.

ClegG, R. A. \& Skyrme, J. E. (I973). The effects of iron-limited growth on the reduced nicotinamide adenine dinucleotide dehydrogenase activity and the membrane proteins of Candida utilis mitochondria. Biochemical Journal 136, 1029-1037.

Dietrich, J. \& HenNing, U. (1970). Regulation of pyruvate dehydrogenase complex synthesis in Escherichia coli K I2. Identification of the inducing metabolite. European Journal of Biochemistry 14, 258-269.

FARRAND, S. K. \& TABER, H. W. (1973). Physiological effects of menaquinone deficiency in Bacillus subtilis. Journal of Bacteriology Ir5, 1035 -1044.

Fortnagel, P. \& Freese, E. (I968). Analysis of sporulation mutants. II. Mutants blocked in the citric acid cycle. Journal of Bacteriology 95, I43I-I 438.

Gibson, F. \& Cox, G. B. (1973). The use of mutants of Escherichia coli $\mathrm{KI} 2$ in studying electron transport and oxidative phosphorylation. Essays in Biochemistry $9, \mathrm{I}-29$.

HADDOCK, B. A. (1973). The reconstitution of oxidase activity in membranes derived from a 5-aminolaevulinic acid-requiring mutant of Escherichia coli. Biochemical Journal 136, 877-884.

HADDOCK, B. A. \& SHAIRER, H. U. (1973). Electron transport chains of Escherichia coli. Reconstitution of respiration in a 5-aminolaevulinic acid-requiring mutant. European Journal of Biochemistry 35, 34-45.

Kogut, M. \& Lightbown, J. W. (I962). Selective inhibition by 2-heptyl-4-hydroxyquinoline- $N$-oxide of certain oxidation-reduction reactions. Biochemical Journal 84, 368-382.

LiGHT, P. A. (1972a). Influence of environment on mitochondrial function in yeast. Journal of Applied Chemistry and Biotechnology 22, 509-526.

Light, P. A. (1972 b). Mitochondrial effects of copper-limited growth of Torulopsis utilis. FEBS Letters $\mathbf{1 9}$, 319-322. 
Light, P. A. \& GaRLAND, P. B. (1971). A comparison of mitochondria from Torulopsis utilis grown in continuous culture with glycerol, iron, ammonium, magnesium or phosphate as the limiting nutrient. Biochemical Journal 124, I23-I 34.

Lowry, O. H., Rosebrough, N. J., Farr, A. L. \& Randall, R. J. (195I). Protein measurement with the Folin phenol reagent. Journal of Biological Chemistry 193, 265-275.

Miki, K., Sekuzu, I. \& Okunuki, K. (1967). Cytochromes of Bacillus subtilis. I. Cytochrome system in the particulate fraction. Report of Scientific Works. Faculty of Science, Osaka University 15, 33-58.

Mindich, L. (1970). Membrane synthesis in Bacillus subtilis. I. Isolation and properties of strains bearing mutations in glycerol metabolism. Journal of Molecular Biology 49, 415-432.

OHNE, M., RutberG, B. \& HoCH, J. A. (1973). Genetic and biochemical characterization of mutants of Bacillus subtilis deficient in succinate dehydrogenase. Journal of Bacteriology $\mathbf{1 1 5}, 738-745$.

ORnston, L. N. \& StanieR, R. Y. (I966). The conversion of catechol and protocatechuate to $\beta$-ketoadipate by Pseudomonas putida. I. Biochemistry. Journal of Biological Chemistry 24I, 3776-3786.

TоснікUво, K. (197I). Changes in terminal respiratory pathways of Bacillus subtilis during germination, outgrowth and vegetative growth. Journal of Bacteriology ro8, 652-661.

Wilson, A. C. \& PARDEE, A. B. (1962). Regulation of flavin synthesis by Escherichia coli. Journal of General Microbiology 28, 283-303.

YANG, C. C. \& Legallais, V. (1954). A rapid and sensitive recording spectrophotometer for the visible and ultraviolet region. I. Description and performance. Reviews of Scientific Instruments 25, 80I-807. 